\title{
One-Trial Memory for Object-Place Associations after Separate Lesions of Hippocampus and Posterior Parahippocampal Region in the Monkey
}

\author{
Ludise Malkova $^{1}$ and Mortimer Mishkin ${ }^{2}$ \\ ${ }^{1}$ Department of Pharmacology, Georgetown University Medical Center, Washington, DC 20007, and 2Laboratory of Neuropsychology, National Institute of \\ Mental Health, Bethesda, Maryland 20892
}

\begin{abstract}
In earlier studies of one-trial spatial memory in monkeys (Parkinson et al., 1988; Angeli et al., 1993), severe and chronic memory impairment for both object-place association and place alone was found after ablation of the hippocampal formation. The results appeared to provide the first clear-cut evidence in the monkey of the essential role of the hippocampus in spatial memory, but that interpretation neglected the inclusion in the lesion of the underlying posterior parahippocampal region. To determine the separate contributions of the hippocampus and posterior parahippocampal region to these spatial forms of one-trial memory, we trained 10 rhesus monkeys, as before, to remember the spatial positions of either two different trial-unique objects overlying two of the wells in a three-well test tray (object-place trials) or simply two of the three wells (place trials). Six of the monkeys then received ibotenic acid lesions restricted to the hippocampal formation (group H), and the four others received selective ablations of the posterior parahippocampal region (group P), comprising mainly parahippocampal cortex, parasubiculum, and presubiculum. Group $\mathrm{H}$ was found to be completely unaffected postoperatively on both types of trials, whereas group P sustained an impairment on both types equal in magnitude to that observed after the combined lesions in the original studies. Thus, contrary to the previous interpretation, one-trial memory for object-place association and, perhaps more fundamentally, one-trial memory for two different places appear to be critically dependent not on the hippocampal formation but rather on the posterior parahippocampal region.
\end{abstract}

Key words: parahippocampal cortex; hippocampus; object-place associations; location memory; ibotenic acid; rhesus monkeys

\section{Introduction}

In a previous study, one-trial memory for object-place associations was severely impaired by aspiration of the hippocampus but not by aspiration of the amygdala (Parkinson et al., 1988). The impairment after hippocampal removal was taken as evidence that the primate hippocampus serves the same selective role in spatial memory that had been established earlier for the rodent hippocampus (O'Keefe and Nadel, 1978). Yet whether objectplace recognition is in fact hippocampal dependent is still uncertain, for hippocampal aspiration also results in extensive damage to posterior parahippocampal tissue lying caudal to the rhinal cortices. This tissue, consisting mainly of the parahippocampal cortex (areas TF and TH) and parasubiculum/presubiculum, receives direct projections from many areas that participate in processing visuospatial information, e.g., posterior parietal, posterior cingulate, retrosplenial, and dorsolateral prefrontal cortices (Seltzer and Pandya, 1976, 1984; Selzter and van Hoesen, 1979; Pandya et al., 1981; Goldman-Rakic et al., 1984; Selemon and Goldman-Rakic, 1988; Cavada and Goldman-Rakic, 1989; Andersen et al., 1990; Suzuki and Amaral, 1994; Morris et al.,

\footnotetext{
Received Aug. 27, 2002; revised Dec. 10, 2002; accepted Dec. 17, 2002.

This work was supported by the National Institute of Mental Health/Intramural Research Program and National Institutes of Health Grants AG14580, HD3997, and NS20576 to L.M. We thank J. Chaudhuri, E. Pixley, M. Belcher, R. Duntz, E. Sharp, and R. Gupta for assistance with the experiments, B. Lowther for help with the figures, and R. C. Saunders for valuable comments on this manuscript.

Correspondence should be addressed to Dr. Ludise Malkova, Department of Pharmacology, Georgetown University, W217 NRB, 3950 Reservoir Road NW, Washington, DC 20007. E-mail: malkoval@georgetown.edu. Copyright $\odot 2003$ Society for Neuroscience $\quad 0270-6474 / 03 / 231956-10 \$ 15.00 / 0$
}

1999a,b; Ding et al., 2000), thereby raising the possibility that damage to the posterior parahippocampal region contributed significantly to the impairment in object-place recognition.

The Parkinson et al. (1988) experiment raised another issue that was left unsettled. Although the results had revealed equivalent deficits on both object-place and place trials (see below), it seemed that the deficit on place trials could have been caused by interference from the concomitant testing on object-place trials, because these two types of trials were identical during the sample phase, differing only at the time of choice. Thus, the monkeys might have failed place trials because they had tried unsuccessfully to form object-place associations in both trial types. However, that possibility was ruled out by a follow-up study (Angeli et al., 1993), which demonstrated that performance on place trials was impaired just as severely as before although object-place trials were never presented. This finding suggests that the basic contribution of the tissue damaged by aspiration of the hippocampus could be to place memory rather than to object-place association per se.

To examine these issues, we assessed the separate roles of the hippocampus and posterior parahippocampal region in one-trial memory both for places and for object-place pairings by selectively damaging the hippocampus with a neurotoxin in one group of animals and, in another group, ablating the posterior parahippocampal region while leaving the hippocampus intact.

An abstract of this work has been published previously (Malkova and Mishkin, 1997). 


\section{Materials and Methods}

\section{Subjects}

The subjects were 10 experimentally naive rhesus monkeys (Macaca mulatta), 3 females and 7 males, weighing $4-6 \mathrm{~kg}$ at the beginning of the study. They were housed individually in rooms with automatically regulated lighting (12 hr light/dark cycle) and were maintained on primate chow (No. 5038; PMI Feeds, St. Louis, MO) supplemented with fresh fruit. Water was available ad libitum. The study was conducted under a protocol approved by the Animal Care and Use Committee of the $\mathrm{Na}$ tional Institute of Mental Health and in accordance with the Guide for Care and Use of Laboratory Animals adopted by the National Institutes of Health.

After completing preoperative training, the monkeys were divided into two surgical groups that were balanced for preoperative learning and performance scores. Six monkeys ( 2 female and 4 male) received bilateral lesions of the hippocampal formation made by injections of ibotenic acid (group H), and four monkeys (1 female and 3 male) received bilateral aspiration lesions of the posterior parahippocampal region (group P).

Each group's final preoperative performance served as a baseline for assessing its postoperative performance, just as in Parkinson et al. (1988). The two groups' postoperative scores were then compared with each other as well as with those of three of the monkeys from the original study [cases H1 to H3 (Parkinson et al., 1988)] that had received hippocampal removal by aspiration (here labeled group H-Asp).

\section{Apparatus and materials}

The apparatus and stimuli were identical to those described by Parkinson et al. (1988). The monkeys were trained in a Wisconsin general testing apparatus inside a darkened, sound-shielded room. Extraneous sound masking was provided by a white-noise generator. The test tray, which was located at the level of the floor of the monkey's transport cage, contained three food wells spaced $18 \mathrm{~cm}$ apart and aligned $14 \mathrm{~cm}$ in front of the cage. The test compartment was illuminated with a $60 \mathrm{~W}$ incandescent bulb, but the monkey's compartment was always unlit. The stimuli consisted of 180 different junk objects that varied widely in color, shape, size, and texture. For each object, an exact duplicate was available. The objects were stored in 18 boxes, each of which contained 10 objects together with their duplicates. Different numbers of objects were required at different stages, with the final stage requiring the use of 48 different objects per session. In this stage, six boxes were used per session. The boxes were used in sequence, and thus at least $2 \mathrm{~d}$ intervened between presentations of the objects contained in a given box.

\section{Behavioral procedure}

The behavioral methods were also identical to those described in Parkinson et al. (1988). As detailed below, the monkeys were trained by approximation to perform the one-trial object-place association task, which, in its final form, proceeded as follows (Fig. 1). On the sample phase of each trial, the animal displaced two trial-unique objects overlying two randomly chosen wells in the three-well test tray. After a 6 sec delay, one of the sample objects was duplicated, and the two identical objects were presented overlying either both of the originally covered wells (objectplace trials) or one of these wells and the third (place trials). To uncover a reward, the animal had to choose whichever object occupied the same location it had occupied in the sample phase. Because the animal could not predict which of the two objects would be duplicated, correct choice on the object-place trials required remembering the locations of both objects after seeing each in its position just once, with new objects appearing as the samples on each succeeding trial. Although the animal also could not predict which trials would be place trials, it was sufficient on these trials simply to remember which wells had been covered in the sample phase, independent of which objects had been used.

Preoperative training and testing. The monkeys were first trained to displace three different objects, used only for this preliminary training, presented one at a time over one of the three wells in a pseudorandom sequence. Uncovering the well revealed a reward, which consisted of either a banana pellet (150 mg) (Noyes, Lancaster, NH) or a raisin, according to the animal's preference. When the monkeys readily displaced the objects, formal training began, which included three stages (stages

\section{OBJECT-PLACE TRIALS PLACE TRIALS}

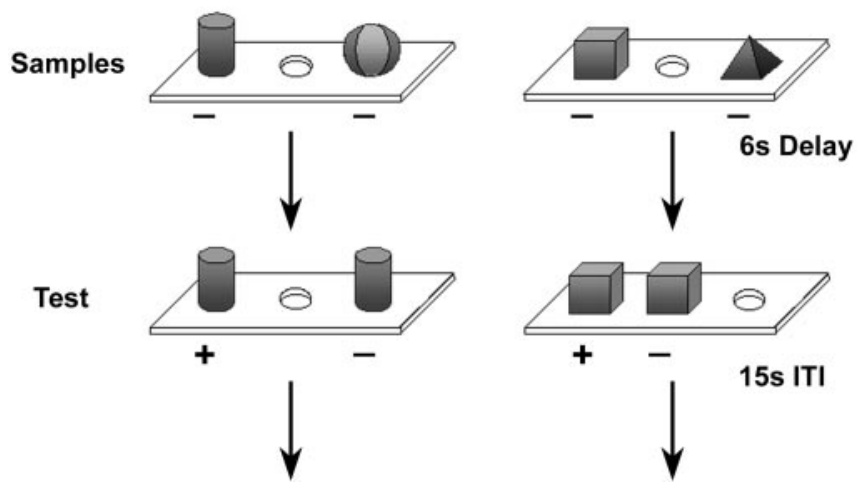

Figure 1. One-trial object-place association task. This figure shows a schematic drawing of the final stage of the task, in which an unlike pair of unbaited objects was presented in the sample phase. In the test phase, one of the two sample objects together with its exact duplicate were presented either over the same two food wells that were used in acquisition (OBJECTPLACE TRIALS) or over one of the food wells used for acquisition and over the third, previously unused food well (PLACE TRIALS). Twelve of each trial type were intermixed within a session. ITI, Intertrial interval.

1-3) preceding the final stage (stage 4). In all stages, each trial consisted of two parts, a sample phase and a choice test.

In stage 1 , the monkey was trained on a variation of delayed matchingto-sample, in which both a trial-unique object and its location served as redundant memory cues. For acquisition, the monkey was required to displace a single, unbaited, sample object, which was placed over each of the three food wells in a pseudorandom order. After a $6 \mathrm{sec}$ delay, the monkey was given a choice test in which the sample, covering the same food well as before, was paired with an unlike object covering one of the other two food wells, and the animal found a reward if it chose the sample object in its original location. In stage 2 , the unbaited sample object again appeared over one of the three food wells, but the two objects used for the choice test were identical (i.e., the sample plus its duplicate). On the choice test, one object was presented in the same location in which it had appeared during the sample presentation, and the other was presented in one of the two remaining locations according to a pseudorandom sequence. Thus, at this stage, only the location of the sample object could serve as a memory cue, and the monkey found the reward if it chose the object in that location. In each of these first two stages, the monkeys were trained in daily sessions of 30 trials separated by $15 \mathrm{sec}$ intertrial intervals, $5 \mathrm{~d}$ per week, until they reached a criterion of $90 \%$ correct responses on each of 2 consecutive days.

Stage 3 consisted of three subtests, each involving a different pair of the three food wells in the sample phase of the trials. Starting with the first subtest, for which the sample phase involved food wells 1 and 3 , an unlike pair of unbaited objects was presented, and the monkey was required to displace both. Then, after a 6 sec delay, one of the two sample objects together with its duplicate were presented either over food wells 1 and 3 or over one of these and over food well 2. Thus, half of the trials (first type above) (Fig. 1, left) were object-place trials, which the monkey could solve only by associating each sample object with its location, whereas the other half (second type) (Fig. 1, right) were place trials, which the monkey could solve simply by remembering the locations of the two sample objects (or, alternatively, by remembering the location of the uncovered well in the sample phase and then avoiding it in the choice test). This procedure yielded four different trial configurations per subtest. Testing continued for 24 trials per day ( 6 each of the 4 configurations) until the monkey reached the criterion of $90 \%$ correct responses on each of 2 consecutive days. After reaching criterion, the monkey was transferred to the second subtest, in which only food wells 1 and 2 were used during the sample phase, and, finally, to the third subtest, in which only food wells 2 and 3 were used during this phase. In other respects, the second and third subtests were identical to the first subtest. 
Finally, in stage 4 (Fig. 1), trials of the three subtests of stage 3 were intermixed in a balanced, pseudorandom order. Two each of the 12 different trial configurations across subtests in stage 3 were combined within a single test session. Otherwise, the testing procedure was identical to that in stage 3, with the trials equally divided between object-place and place trials. Testing continued for $25 \mathrm{~d}$ ( $5 \mathrm{~d}$ /week for 5 weeks), and the average score across the 5 weeks was used as the preoperative baseline of performance for each animal. [Three of the animals $(\mathrm{H} 3,5,6)$ scored $<70 \%$ correct during either the second or third week of stage 4 ; they were therefore given 2 additional weeks of testing on this stage, and their preoperative baseline was taken as the average score across weeks 3-7 instead of across weeks 1-5].

Postoperative testing. Postoperatively, the monkeys were tested on the final stage (stage 4 ) of the task only, for a period of $75 \mathrm{~d}$ ( $5 \mathrm{~d} /$ week for 15 weeks).

\section{Magnetic resonance imaging}

Several days before surgery, each monkey received a T1-weighted magnetic resonance imaging (MRI) brain scan. Postoperatively, each monkey received at least one scan (either T1- or T2-weighted), with the total number of scans per monkey varying between 2 and 10 . For each scanning session, the monkey was anesthetized with a $4: 1(\mathrm{v} / \mathrm{v})$ mixture of ketamine (ketamine hydrochloride, $10-20 \mathrm{mg} / \mathrm{kg}$, i.m., to effect) and xylazine $(0.2-0.4 \mathrm{mg} / \mathrm{kg}, \mathrm{i} . \mathrm{m}$.) and placed in a specially constructed nonferrous stereotaxic frame (Saunders et al., 1990). MRI was performed in a 1.5 T Signa unit (GE Medical Systems, Milwaukee, WI) using a 5 inch general purpose surface coil. T1-weighted MR images were obtained using a three-dimensional volume spoiled grass pulse sequence [echo time (TE) 6; repetition time (TR) 25; flip angle 30; number of excitations $(\mathrm{NEX})=4]$. Field of view $(\mathrm{FOV})$ was $11 \mathrm{~cm}$, slice thickness was $1 \mathrm{~mm}$, and in-plane resolution was $0.204 \mathrm{~mm}^{2}$. T2-weighted scans were obtained using a two-dimensional spin echo pulse sequence (TE 17; TE2 102; TR 3000; NEX = 3). FOV was $11 \mathrm{~cm}$, slice thickness was $1.5 \mathrm{~mm}$, and in-plane resolution was $0.246 \mathrm{~mm}^{2}$.

The preoperative MRI scans served as a reference for postoperative evaluation of the lesions. In addition, the scans of the monkeys in group $\mathrm{H}$ were used to obtain measurements for calculating stereotaxic coordinates for the ibotenic acid injections (Saunders et al., 1990; Malkova et al., 2001). Postoperatively, three monkeys in group $\mathrm{H}$ (H4-6) received a T2-weighted scan $\sim 1$ week after each unilateral surgery to enable early assessment of lesion extent (Malkova et al., 2001), and all monkeys received at least one T1-weighted scan several months after surgery to evaluate lesion extent while they were still undergoing behavioral testing.

\section{Surgery}

Because a large and potentially lethal amount of ibotenic acid would have been required for a one-stage bilateral lesion of the hippocampus, these surgeries were performed in two stages, left hemisphere followed by right (except for case H5, in which the order was reversed), separated by a minimum of 2 weeks (range, 14-22 d). To ensure that both surgical groups were treated similarly, aspiration lesions of the posterior parahippocampal region were also performed in two stages, left hemisphere followed by right, and also separated by at least 2 weeks (range, 15-17 d).

After the monkey was sedated with ketamine hydrochloride $(10 \mathrm{mg} /$ $\mathrm{kg}$ ), a surgical level of anesthesia was maintained with isoflurane gas ( $1-2 \%$, to effect) for the duration of surgery, which was performed under aseptic conditions. Monkeys received an intravenous drip solution of isotonic fluids, and their heart rate, respiration rate, blood pressure, expired $\mathrm{CO}_{2}$, and body temperature were monitored throughout the procedure. To prevent potential brain swelling, Mannitol $(30 \% ; 30 \mathrm{ml}$, i.v., at $1 \mathrm{ml} / \mathrm{min}$ ) was administered to the monkeys in group $\mathrm{H}$ toward the end of the series of injections and in group $\mathrm{P}$ at the beginning of the surgery.

Hippocampal lesions. The lesions were intended to include the entire hippocampal formation, consisting of the dentate gyrus, Ammon's horn (subfields CA1-4), and subiculum, including prosubiculum (Rosene and van Hoesen, 1987; Scharfman et al., 2000) (Fig. 2). On the basis of the measurements derived from the preoperative series of T1-weighted images, stereotaxic coordinates were determined for a matrix of injections.
In most cases, the injection sites were separated by $\sim 2 \mathrm{~mm}$ in each plane and were intended on the basis of previous findings to allow diffusion of the ibotenate throughout the area of the intended lesion. A bone flap was made in the appropriate portion of the cranium, and small slits were cut in the dura to allow the 30 gauge needle of a $10 \mu$ l Hamilton syringe, held in a Kopf electrode manipulator (David Kopf Instruments, Tujunga, $\mathrm{CA})$, to be lowered to the target coordinates. The lesions were made by injections of the excitotoxin, ibotenic acid (Regis Chemical, Morton Grove, IL, or Solid Phase Sciences, San Rafael, CA). At each target site, $1-2 \mu l$ of ibotenic acid $(10-15 \mathrm{mg} / \mathrm{ml})$ were injected. To allow diffusion of the ibotenic acid into the extracellular space, and to minimize mechanical damage to the tissue, all injections were made at a rate of $0.2 \mu \mathrm{l} / \mathrm{min}$. After the injections were completed, the bone flap was repositioned, and the wound was sutured in anatomical layers.

The first three cases (H1-3) received a total of 14.6-14.8 $\mu$ l of ibotenate per hemisphere distributed among 12-13 injection sites. Because histological evaluation indicated that each of these lesions was incomplete, the amount for the next surgical series $(\mathrm{H} 4-6)$ was increased to a total of $17.4-25.2 \mu \mathrm{l}$ of ibotenate per hemisphere distributed among 13-19 injection sites. In all three monkeys of the second series, the postoperative T2-weighted MR images indicated that the lesion was still incomplete in at least one hemisphere. These monkeys therefore received additional injections in those hemispheres $122 \mathrm{~d}$ (H4), $57 \mathrm{~d}$ (H5), and $14 \mathrm{~d}$ (H6) after the initial ones.

Posterior parahippocampal lesions. These removals, which were made via a supralabyrinthine approach, were intended to include the parahippocampal cortex (areas TF and TH) and the parasubiculum/presubiculum (Figs. 3, 4). After part of the temporal bone was removed, the dura mater was opened and reflected, the posterior part of the inferior temporal cortex was gently lifted, and the occipitotemporal sulcus was identified. The boundaries of the cortical lesion were the same as those in the monkeys given hippocampal ablations in the earlier studies (Parkinson et al., 1988; Angeli et al., 1993), with the exception of the rostral boundary (Fig. 3). Although the lesions in the earlier experiments extended rostrally to include approximately the posterior half of the entorhinal cortex, those in the present experiment extended only as far forward as the caudal tip of the rhinal sulcus in an attempt to spare completely the entorhinal/perirhinal areas. The lesion was bounded caudally by a coronal line drawn at the rostral limit of the inferior occipital sulcus and ventrolaterally by the fundus of the occipitotemporal sulcus. The cortex on the ventromedial surface of the brain between the fundus of the occiptotemporal sulcus and the brainstem was aspirated with a 22 gauge metal sucker. The cranial defect was then covered by Teflon (Saunders and O'Boyle, 1993), and the wound was closed in anatomical layers.

All monkeys received a preoperative and postoperative treatment regimen consisting of dexamethasone sodium phosphate $(0.4 \mathrm{mg} / \mathrm{kg})$ and Di-Trim (24\% w/v solution, $0.1 \mathrm{ml} / \mathrm{kg}$, i.m.; Syntex Animal Health, West Des Moines, IA) for $1 \mathrm{~d}$ before surgery and 1 week after surgery to minimize trauma and prevent infection, respectively. They also received postoperative analgesics as determined in consultation with the facility veterinarian.

\section{Histology}

At the completion of behavioral testing, monkeys were given an overdose of barbiturate (sodium pentobarbital, $100 \mathrm{mg} / \mathrm{kg}$, i.m.) and perfused through the heart with normal saline followed by aldehyde fixatives. The brains were removed, photographed, and frozen, $50 \mu \mathrm{m}$ coronal sections were cut on a freezing microtome, and every fifth section was mounted, stained with thionin, and coverslipped. Histological sections were examined microscopically, and regions of cell loss and gliosis in group $\mathrm{H}$ and the extent of lesions in group P were plotted on drawings of normal coronal sections. The area of intended as well as unintended damage to the surrounding structures was measured in square millimeters on the drawing of each section containing a lesion by tracing the borders of the lesion with a digital tablet system (Wacom Intuos2) linked to a computer. 


\section{Intended}
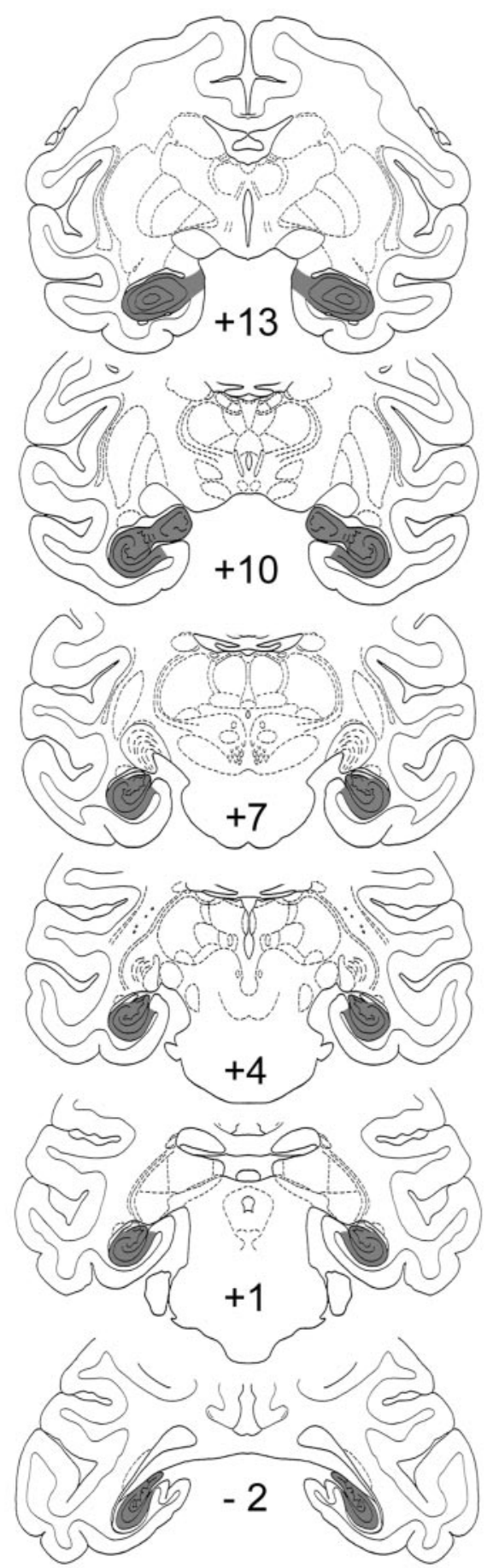

$\mathrm{H} 4$
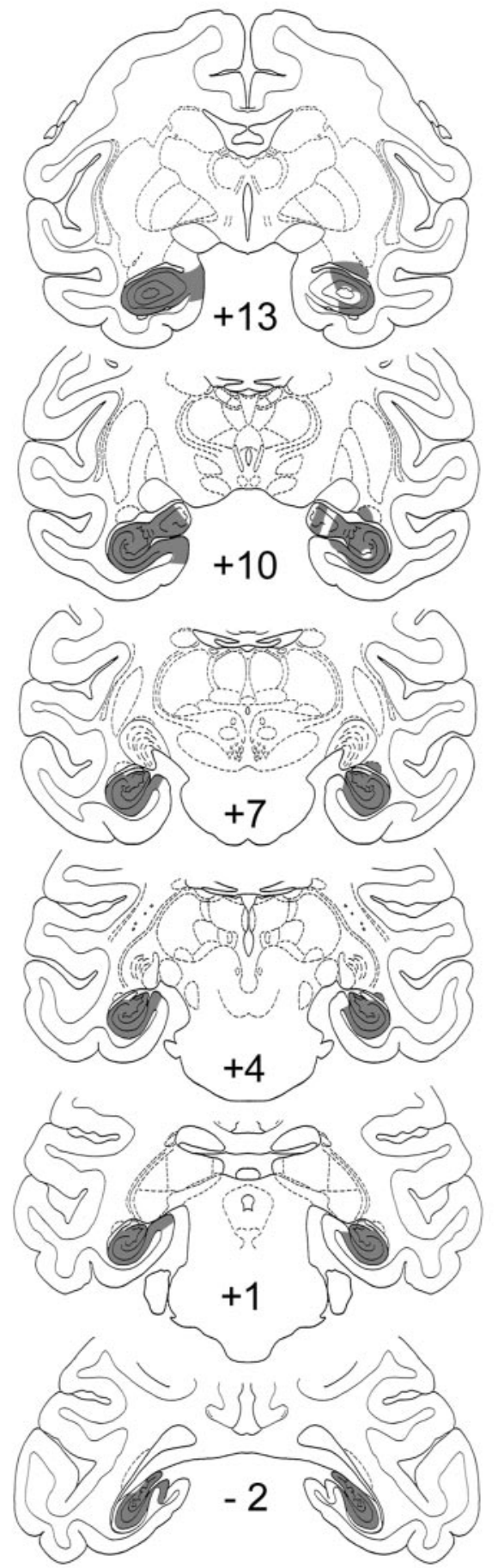

H 6
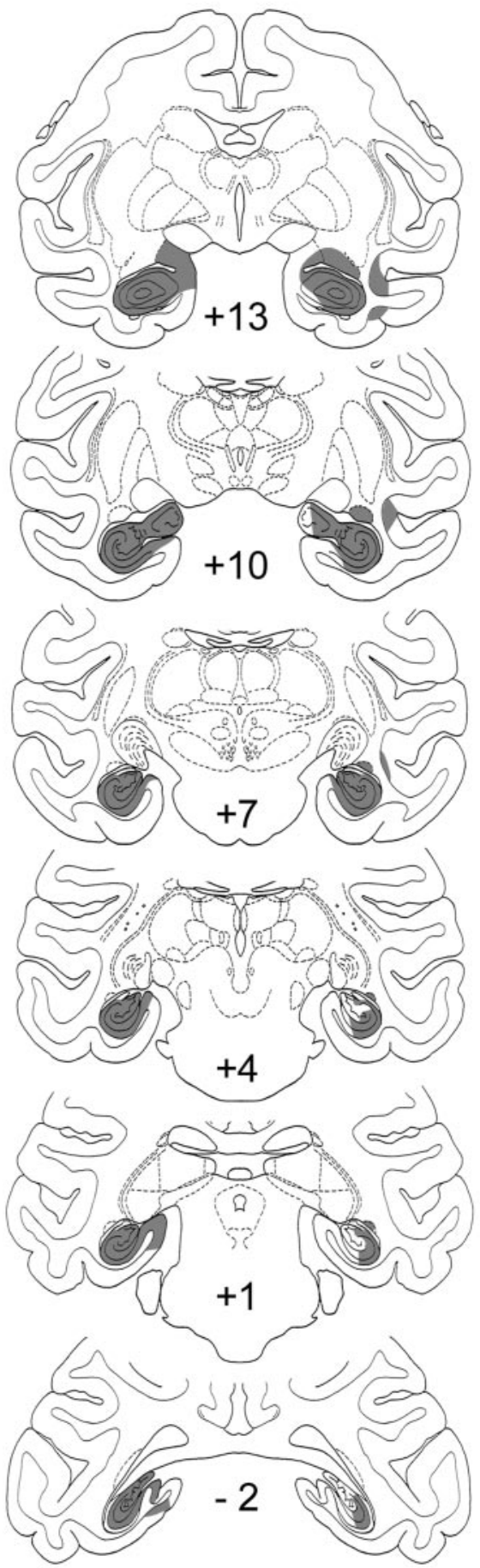

Figure 2. Intended lesion of the hippocampal formation (left column) and actual lesions in two representative cases ( $H 4$ and $H 6$; middle and right columns, respectively) transferred to standard coronal sections. Numerals indicate distance in millimeters from the interaural vertical plane.

\section{Results}

\section{Lesion assessment}

The volume of damage to all areas of interest was expressed as a percentage of normal volume and is presented for each case in Table 1.

Hippocampal lesions

As indicated in the section on surgery, the damage to the hippocampal formation in the first three cases (H1-3) was incom- plete (mean, 41\%; range, 30-55\%) (Table 1). In the other three cases (H4-6), however, the injection of a larger volume of ibotenic acid initially, as well as the addition later of a second series of injections, resulted in more substantial lesions (mean, $81 \%$, range, 70-91\%) (Figs. 2, 5). All animals sustained unintended bilateral damage to the parasubiculum/presubiculum (range, $28-62 \%$ ), but unintended damage to other areas outside the hippocampal formation was only minimal. This included minor 

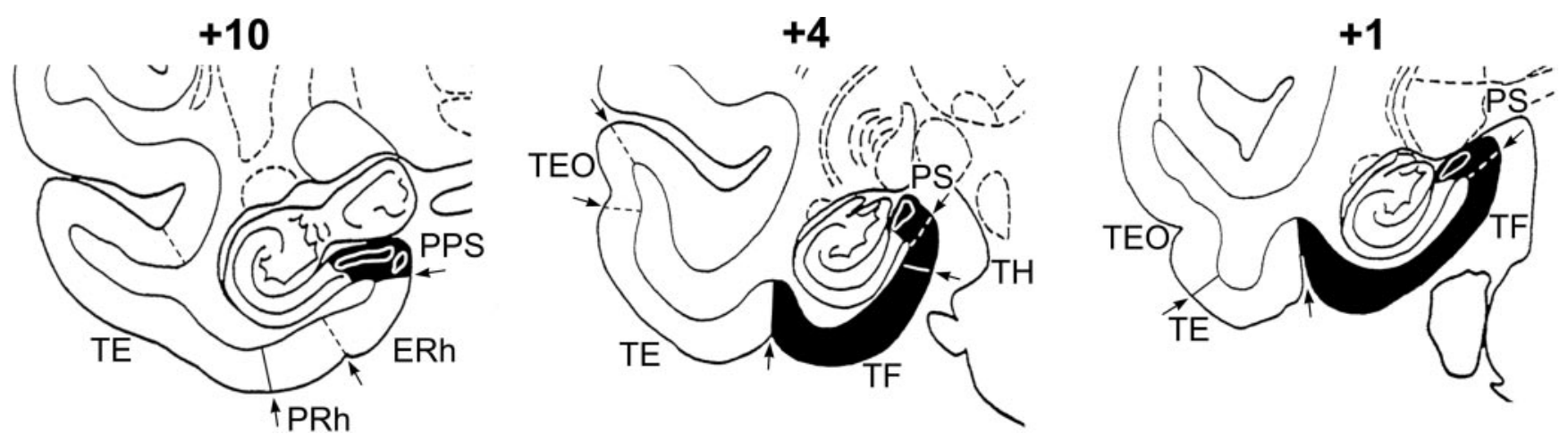

Figure 3. Intended lesion of the posterior parahippocampal region is in black. Numerals indicate distance in millimeters from the interaural vertical plane. PPS, Parasubiculum/presubiculum; PS, presubiculum; ERh, entorhinal cortex; PRh, perirhinal cortex; TH, TF, parahippocampal cortical areas (von Bonin and Bailey, 1947); TE, TE0, visual cortical areas (von Bonin and Bailey, 1947).

damage to the parahippocampal cortex, bilaterally in three cases (H1-3) and unilaterally in three ( $\mathrm{H} 4-6)$, and a small amount of unilateral entorhinal damage in two cases ( $\mathrm{H} 2$ and $\mathrm{H} 4)$.

\section{Posterior parahippocampal lesions}

Three of the monkeys in group $\mathrm{P}(\mathrm{P} 1-3)$ had substantial bilateral damage to the parahippocampal cortex (range, 75-87\%) and to the parasubiculum/presubiculum (range, 53-70\%) (Fig. 4). Surrounding areas invaded by the lesions in these three cases include the entorhinal and perirhinal cortices, primarily unilateral in two (P1 and P3) and bilateral in the third (P2), although the damage to the two areas in this case averaged $<20 \%$. In addition, all three cases sustained some damage to visual cortical areas TE (4-17\%) and TEO (12-28\%), as well as moderate to severe encroachment of the white matter of the parahippocampal gyrus.

Unlike the lesions in these three cases, the one in P4 (Fig. 4) did not reach the dorsomedial portion of the gyrus. Thus, although this case sustained damage to the parahippocampal cortex in an amount $(78 \%)$ comparable with that in the other three cases, the parasubiculum/presubiculum was intact, as were the perirhinal/entorhinal cortices, as well as the white matter of the parahippocampal gyrus. Conversely, this case sustained the largest amount of unintended bilateral damage to areas TE (18\%) and TEO (43\%). Because both the extent of lesion and postoperative performance of $\mathrm{P} 4$ differed substantially from those of the other three animals in the group, the results of $\mathrm{P} 4$ will be treated separately.

\section{Behavioral assessment}

Unlike the animals of the original study (Parkinson et al., 1988), which performed slightly but significantly better on place trials than on object-place trials both before and after operation, the animals in the current study performed throughout at approximately the same level on both types of trials (Table 2). The explanation for this difference in the results of the two studies is unknown, because the same training procedures were used in both and they yielded the same overall levels of preoperative performance in both (see below). Given the similarity of scores on the two different trial types in the present study, however, the scores were collapsed across this variable for all of the following analyses.

Preoperatively, the 10 animals in this study attained criterion on stages $1-3$ in an average of $\sim 2200$ trials and 450 errors, and they then scored an average of $81 \%$ correct responses on the performance test, stage 4 (Table 2, Fig. 6). Statistical comparisons confirmed that the animals assigned to groups $\mathrm{H}$ and $\mathrm{P}$ did not differ significantly on any of these measures.

Postoperatively, however, there were clear differences be- tween the two groups: group $\mathrm{H}$ continued to perform at the $80 \%$ level just as before, whereas group P (i.e., cases P1-3) fell from this level to an average of $\sim 60 \%$ correct. As indicated in Table 2 , the 75 postoperative sessions were divided into three blocks of 25 sessions each, and the scores on these three blocks were subjected to a group-by-block ANOVA. The only significant effect was that for group $(F=28.87 ; \mathrm{df}=1,7 ; p<0.01)$. The fact that neither blocks nor the interaction of group by blocks was significant indicates that the animals in both groups performed at a fairly stable level throughout postoperative testing.

As noted earlier, the hippocampal damage in three monkeys of group $\mathrm{H}(\mathrm{H} 1-3)$ averaged only $41 \%$, whereas in the three others $(\mathrm{H} 4-6)$ it averaged $81 \%$. Statistical comparison failed to reveal any difference in performance between these two subgroups either before or after operation. This negative result was confirmed by correlation analysis, which likewise failed to reveal a significant relationship between extent of hippocampal damage (range, 30-91\%) and postoperative performance (range, $74-89 \% ; r=0.24 ; p>0.05)$. By contrast, among the animals in group $\mathrm{P}$, case $\mathrm{P} 4$ with the relatively small amount of damage to the intended locus, particularly to the parasubicular/presubicular portion of the posterior parahippocampal region, was far less impaired than the three others in that group, falling only $7 \%$ from its preoperative level of performance compared with an average drop for the others of $22 \%$ (Table 2).

Preoperatively, there were no differences between group $\mathrm{H}$-Asp of the original study (see Subjects) and the two groups from the current study either in trials and errors to attain criterion on stages 1-3 or in preoperative performance on stage 4 . Postoperatively, however, an ANOVA yielded a significant effect of group $(F=27.25$; $\mathrm{df}=2,9 ; p<0.01)$. Pairwise comparisons (Tukey) indicated that group $\mathrm{H}$-Asp performed significantly more poorly than group $\mathrm{H}(p<0.01)$ but not more poorly than group $\mathrm{P}(p=0.83)$.

\section{Discussion}

The present results suggest the following: (1) recognition memory for object-place association depends not on the hippocampus but rather on the posterior parahippocampal region; (2) within this region, both the parahippocampal cortex and the parasubiculum/presubiculum make essential contributions; and (3) the basic contribution of both subdivisions of this region is to place memory, with object-place memory constituting a derivative function. These proposals are each considered in turn below, after which they are discussed in relation to some recent findings on the neural substrates of spatial memory in humans. 


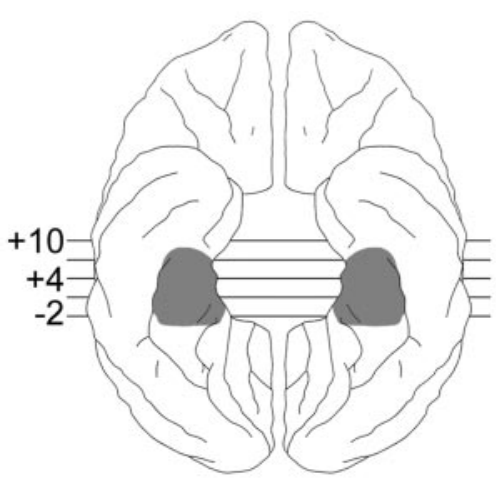

Intended
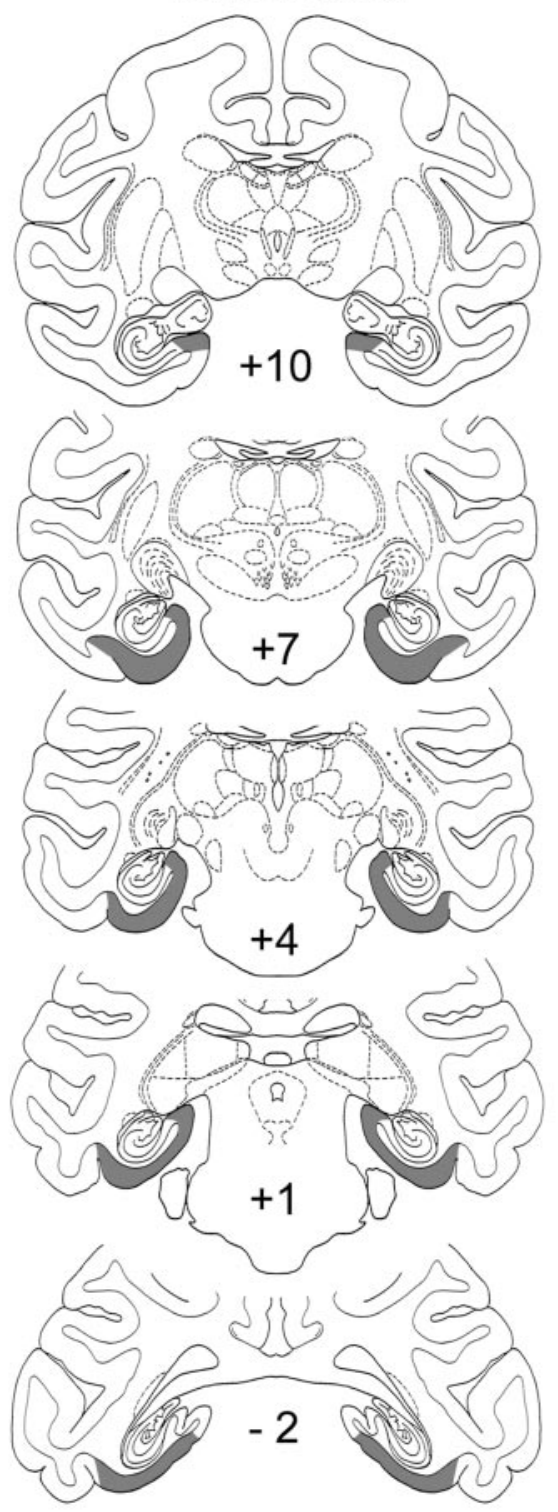

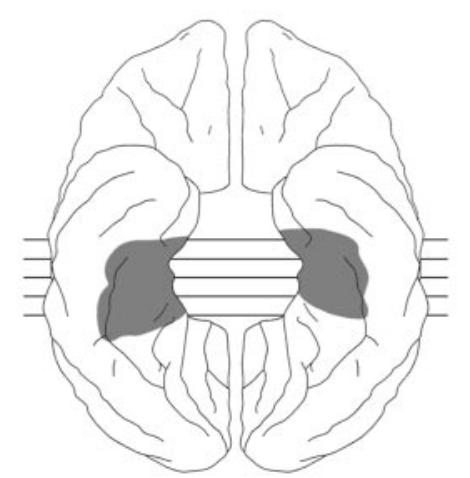

P 2
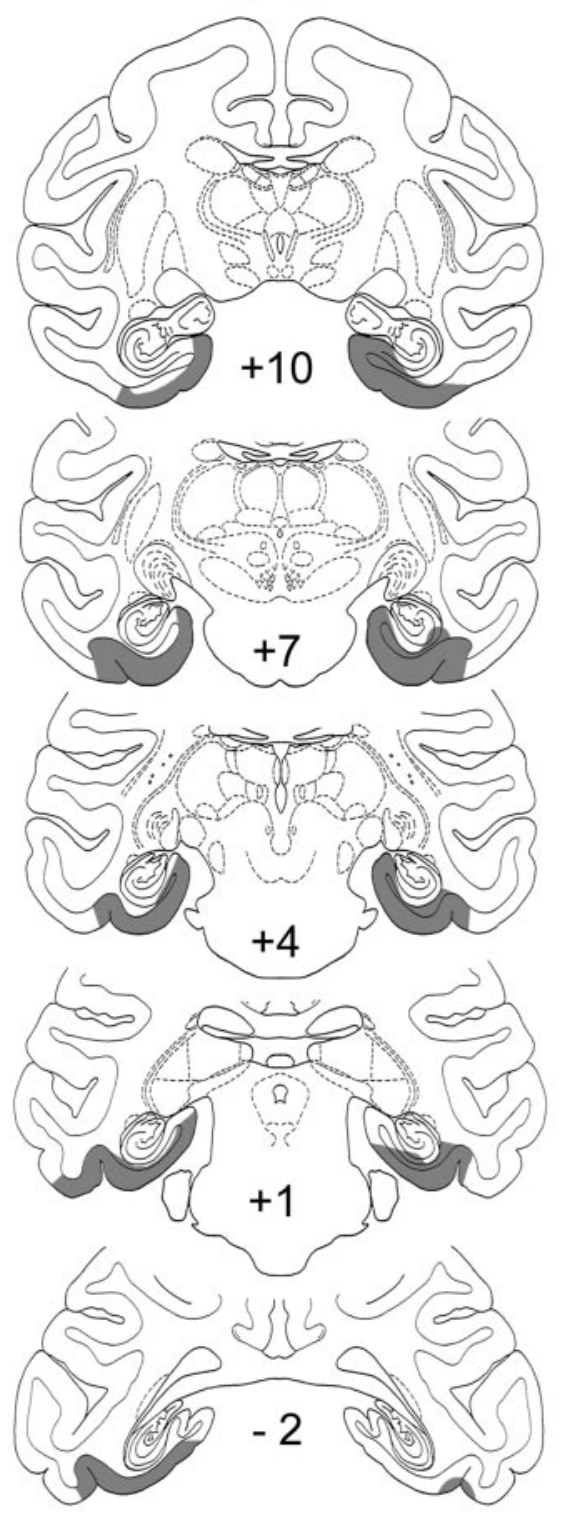

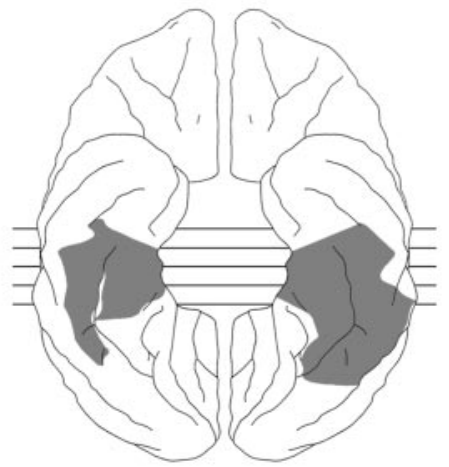

P 4
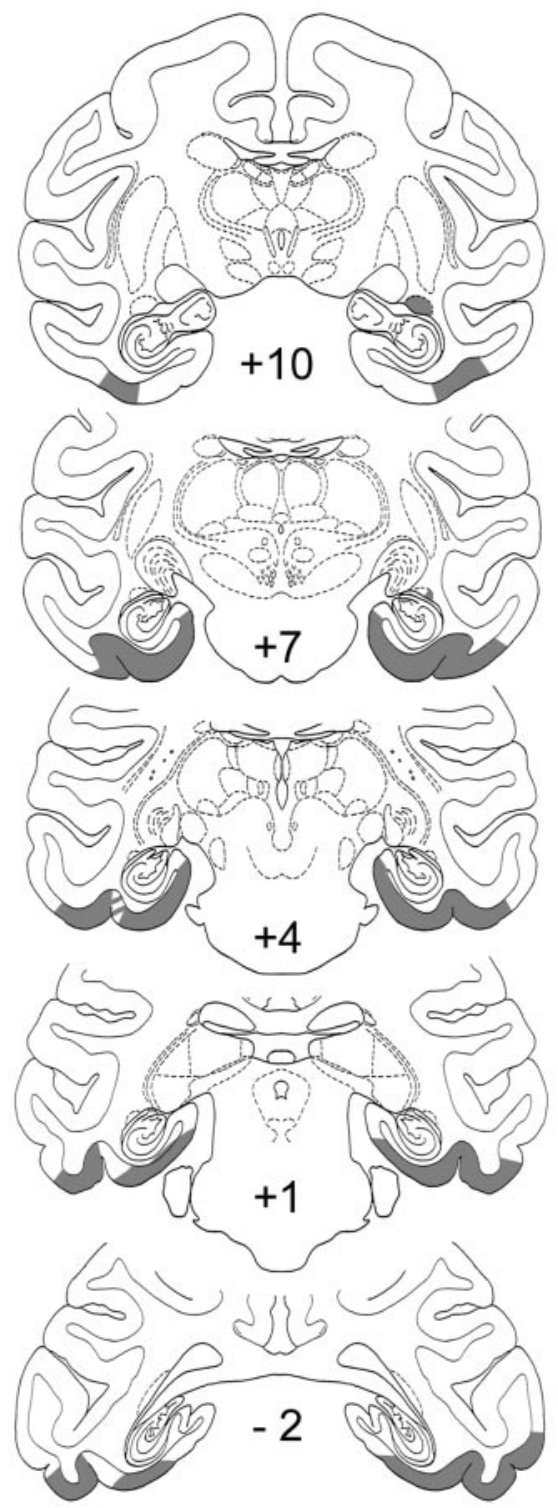

Figure 4. Intended lesion of the posterior parahippocampal region (left column) and actual lesions in two cases ( $P 2$ and P4; middle and right columns, respectively) transferred to standard coronal sections and reconstructed on standard ventral surface views (top). Note sparing of presubicular cortex in case P4. Numerals indicate distance in millimeters from the interaural vertical plane.

Hippocampus versus posterior parahippocampal region The monkeys with excitotoxic hippocampal lesions showed no impairment on the object-place task. Moreover, there was no relationship between performance and extent of hippocampal damage, which varied widely (range, 30-91\%). By contrast, even partial damage to the posterior parahippocampal region, as in case $\mathrm{P} 4$, produced some impairment on the task, and the more extensive damage to this region sustained by the three others in 
Table 1. Extent of damage to medial temporal lobe structures

\begin{tabular}{|c|c|c|c|c|c|c|c|c|c|c|c|c|c|c|c|c|c|c|c|c|c|}
\hline \multirow{2}{*}{$\begin{array}{l}\text { Volume/ } \\
\text { side } \\
\left(\mathrm{mm}^{3}\right) \\
\text { Case }\end{array}$} & \multicolumn{3}{|l|}{$\begin{array}{l}\mathrm{HF} \\
545\end{array}$} & \multicolumn{3}{|c|}{$\begin{array}{l}\text { Para/Presub } \\
74\end{array}$} & \multicolumn{3}{|c|}{$\begin{array}{l}\mathrm{PH} \\
333\end{array}$} & \multicolumn{3}{|c|}{$\begin{array}{l}\text { ERh } \\
174\end{array}$} & \multicolumn{3}{|c|}{$\begin{array}{l}\text { PRh } \\
250\end{array}$} & \multicolumn{3}{|c|}{$\begin{array}{l}\text { TE } \\
915\end{array}$} & \multicolumn{3}{|c|}{$\begin{array}{l}\text { TE0 } \\
282\end{array}$} \\
\hline & $\mathrm{L}$ & $R$ & Mean & $\mathrm{L}$ & $\mathrm{R}$ & Mean & $\mathrm{L}$ & $\mathrm{R}$ & Mean & $\mathrm{L}$ & $\mathrm{R}$ & Mean & L & $\mathrm{R}$ & Mean & $\mathrm{L}$ & $\mathrm{R}$ & Mean & $\mathrm{L}$ & $\mathrm{R}$ & Mean \\
\hline H2 & 64 & 47 & 55 & 42 & 44 & 43 & 7 & 36 & 21 & 0 & 18 & 9 & 0 & 0 & 0 & 0 & 0 & 0 & 0 & 0 & 0 \\
\hline H3 & 24 & 50 & 37 & 56 & 19 & 38 & 15 & 2 & 9 & 0 & 0 & 0 & 0 & 0 & 0 & 0 & 0 & 0 & 0 & 0 & 0 \\
\hline $\mathrm{H} 4$ & 100 & 83 & 91 & 100 & 24 & 62 & 5 & 0 & 2 & 5 & 0 & 3 & 0 & 0 & 0 & 0 & 0 & 0 & 0 & 0 & 0 \\
\hline H6 & 67 & 55 & 61 & 63 & 20 & 42 & 7 & 6 & 7 & 1 & 3 & 2 & 0 & 0 & 0 & 0 & 0 & 0 & 0 & 0 & 0 \\
\hline P1 & 13 & 6 & 9 & 37 & 68 & 53 & 78 & 73 & 75 & 3 & 23 & 13 & 2 & 10 & 6 & 7 & 0 & 4 & 7 & 16 & 12 \\
\hline P2 & 2 & 12 & 7 & 47 & 60 & 54 & 99 & 75 & 87 & 22 & 19 & 21 & 12 & 23 & 18 & 6 & 5 & 6 & 26 & 6 & 16 \\
\hline \multirow[t]{2}{*}{ P3 } & 6 & 12 & 9 & 48 & 92 & 70 & 63 & 92 & 77 & 4 & 46 & 25 & 0 & 21 & 11 & 10 & 23 & 17 & 18 & 37 & 28 \\
\hline & 7 & 10 & 8 & 44 & 73 & 59 & 80 & 80 & 80 & 10 & 29 & 20 & 5 & 18 & 11 & 8 & 9 & 9 & 17 & 20 & 18 \\
\hline
\end{tabular}

HF, Hippocampal formation; PH, parahippocampal cortex; Para/Presub, parasubiculum plus presubiculum; ERh, entorhinal cortex; PRh, perirhinal cortex; TE, area TE; TE0, area TE0; L, left; R, right.
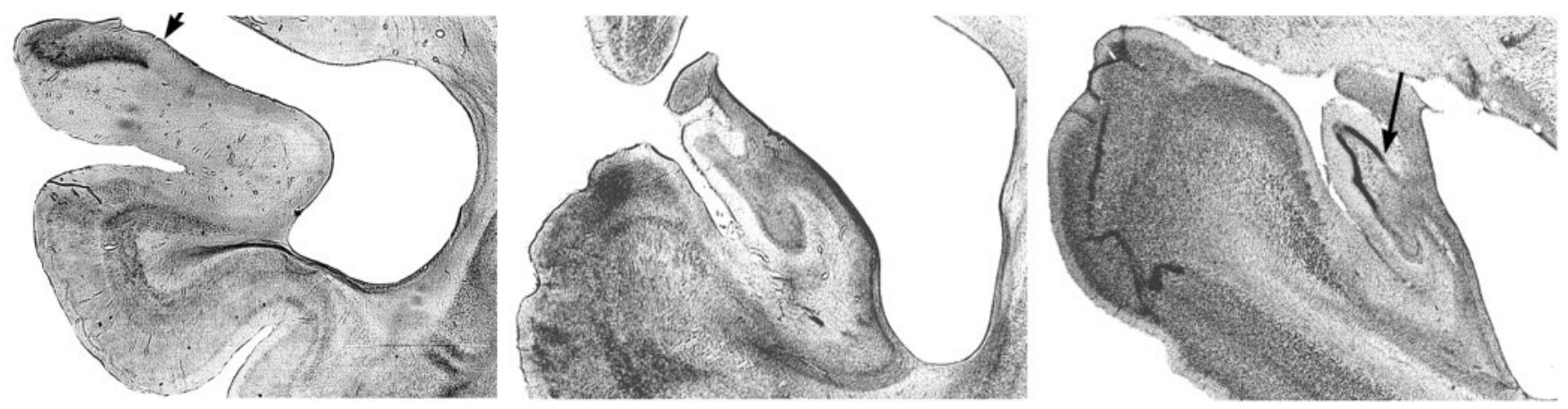

Figure 5. Photomicrographs of coronal sections through the hippocampal lesion in the right hemisphere of case H5. Middle section shows complete cell loss in the hippocampal formation, whereas the others show partial sparing of the hippocampal formation in the area medial to (i.e., to the left of) each arrow. Left, middle, and right sections correspond to sections $+13,+7$, and +1 in Figure 2.

Table 2. Preoperative learning and performance and postoperative performance on object-place task

\begin{tabular}{|c|c|c|c|c|c|c|c|c|c|c|c|c|c|c|c|}
\hline \multirow[b]{2}{*}{ Case } & & \multicolumn{2}{|c|}{$\begin{array}{l}\text { Preoperative } \\
\text { learning }\end{array}$} & \multicolumn{3}{|c|}{ Performance sessions 1-25 } & \multicolumn{3}{|c|}{$\begin{array}{l}\text { Postoperative performance } \\
\text { sessions } 1-25\end{array}$} & \multicolumn{3}{|c|}{$26-50$} & \multicolumn{3}{|c|}{$51-75$} \\
\hline & & $T$ & $E$ & $O P$ & $P$ & Mean & $O P$ & $P$ & Mean & $O P$ & $P$ & Mean & $O P$ & $P$ & Mean \\
\hline H1 & & 1380 & 392 & 76 & 82 & 79 & 78 & 83 & 81 & 87 & 87 & 87 & 86 & 90 & 88 \\
\hline $\mathrm{H} 2$ & & 2122 & 437 & 84 & 77 & 81 & 75 & 78 & 77 & 82 & 81 & 81 & 81 & 83 & 82 \\
\hline H3 & & 3262 & 773 & 72 & 75 & 74 & 71 & 69 & 70 & 74 & 67 & 71 & 73 & 71 & 72 \\
\hline $\mathrm{H} 4$ & & 1536 & 374 & 93 & 85 & 89 & 89 & 88 & 89 & 89 & 85 & 87 & 92 & 87 & 89 \\
\hline $\mathrm{H} 5$ & & 1822 & 274 & 83 & 77 & 80 & 85 & 81 & 83 & 83 & 82 & 82 & 81 & 82 & 82 \\
\hline \multirow[t]{2}{*}{$\mathrm{H} 6$} & & 2157 & 523 & 77 & 79 & 78 & 70 & 79 & 75 & 75 & 82 & 79 & 70 & 77 & 74 \\
\hline & $X$ & 2047 & 462 & 81 & 79 & 80 & 78 & 80 & 79 & 82 & 81 & 81 & 81 & 82 & 81 \\
\hline P1 & & 3918 & 391 & 81 & 80 & 81 & 52 & 63 & 57 & 52 & 66 & 59 & 59 & 62 & 61 \\
\hline P2 & & 1632 & 424 & 87 & 85 & 86 & 56 & 62 & 59 & 64 & 61 & 63 & 66 & 65 & 66 \\
\hline \multirow[t]{2}{*}{ P3 } & & 2942 & 751 & 83 & 80 & 82 & 58 & 57 & 58 & 61 & 58 & 60 & 61 & 61 & 61 \\
\hline & $X$ & 2831 & 522 & 84 & 82 & 83 & 55 & 61 & 58 & 59 & 62 & 61 & 62 & 63 & 63 \\
\hline P4 & & 1050 & 238 & 83 & 83 & 83 & 77 & 74 & 75 & 76 & 76 & 76 & 78 & 77 & 78 \\
\hline
\end{tabular}

$\mathrm{H}$, Bilateral lesions of hippocampal formation; $\mathrm{P}$, bilateral lesions of parahippocampal cortex; $T$, trials; $E$, errors preceding criterion across stages 1 through 3 of preoperative training. Each column of performance sessions represents average performance across 25 test sessions ( 24 trials, each totaling 600 trials) for object-place (OP), place-only (P) trials, and means across the two trial types.

group P caused a deficit as severe as that found in the original study after combined ablation of the hippocampus and the tissue underlying it (group H-Asp). Together, the results thus suggest that the impairment in the original study was caused entirely by the removal of that subhippocampal tissue.

One-trial memory of object-place associations must thus be added to the long list of recognition abilities - including visual and tactile delayed nonmatching-to-sample, as well as recogni- tion of visual-visual, visual-tactile, and object-reward associations - that were originally thought to be mediated by the hippocampus but were later shown to depend primarily on the cortex of the parahippocampal region (for review, see Mishkin et al., 1997). At the same time, memory for object-place association also differs from all the other recognition abilities in that it seems to be critically dependent on the posterior portion of this region, whereas the other abilities are known to depend instead on the 


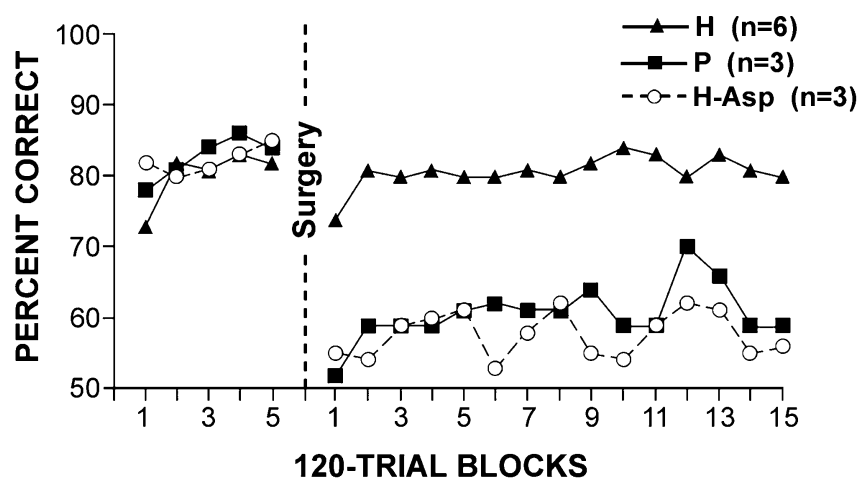

Figure 6. Preoperative baseline and postoperative performance on one-trial object-place association task. Each data point represents average score for a block of five daily sessions (120 trials). $H$, Monkeys with excitotoxic lesions of the hippocampal formation; $P$, monkeys with ablations of the posterior parahippocampal region; $H$-Asp, monkeys with hippocampectomy by aspiration that sustained combined damage to the hippocampus and posterior parahippocampal region in the study by Parkinson et al. (1988).

anterior (i.e., the perirhinal/entorhinal cortices) and not on the posterior portion. However, whether object-place association also requires the rhinal cortices still needs to be determined.

The negative results after selective hippocampal damage resemble those of an earlier experiment (Murray and Mishkin, 1998), in which ibotenate lesions of the hippocampus and amygdala failed to reproduce an impairment on delayed nonmatching-to-location that had been found previously after aspiration of the hippocampus and amygdala (Malkova et al., 1995) and, more recently, of the hippocampus alone (Alvarado et al., 2002). This spatial memory deficit too may therefore have resulted from the associated damage to the posterior parahippocampal region, although this of course is a proposal in need of testing.

By contrast to the above forms of spatial memory, tasks requiring memory of where to reach within complex scenes presented on a computer screen (Gaffan, 1994) or where to find food under objects in an open field did reveal impairment after excitotoxic hippocampal lesions (Murray et al., 1998; Hampstead et al., 2001). However, unlike the delays in the present study, which lasted only a few seconds, the delays in the scenes task lasted several minutes, and those in the open field task lasted up to several hours. Whether these differences in memory demands account for the differential effects of selective hippocampal lesions is considered again below.

\section{Parahippocampal and parasubicular/presubicular cortices} Comparison among the lesions within group $\mathrm{P}$ suggest that the difference in their effects was not associated with differences either in the intended damage to parahippocampal cortex (areas $\mathrm{TF}$ and $\mathrm{TH}$ ), which reached $\sim 80 \%$ in each of the four cases, or in unintended damage to the inferior temporal visual areas (TE and TEO). Indeed, encroachment on these visual areas was greatest in case P4, which was the least affected animal in the group. Although a contribution to the deficit from this unintended damage cannot be ruled out, the behavioral difference within group $\mathrm{P}$ appears to have been caused mainly by the difference in parasubicular/presubicular damage, which was entirely absent in $\mathrm{P} 4$ but averaged nearly $60 \%$ in cases $\mathrm{P} 1-3$. Yet, just as damage to parahippocampal cortex alone was insufficient to produce severe impairment, so too was parasubicular/presubicular damage alone insufficient, because group $\mathrm{H}$ incurred nearly as much damage to the parasubiculum/presubiculum as did P1-3. It seems likely, therefore, that the severe impairment found in these three cases was caused by combined damage to both the parahippocampal and parasubicular/presubicular cortices, a combination that only they sustained.

This proposal is consistent with the anatomical literature (see Introduction), which indicates that both parahippocampal and parasubicular/presubicular cortices receive projections from dorsal visuospatial processing areas, sometimes even from the same neurons (Ding et al., 2000). Because this input courses through the white matter of the posterior parahippocampal region before reaching its targets, invasion of this white matter in cases P1-3 presumably contributed to the effectiveness of the lesion by deafferenting portions of the region that were not damaged directly.

Other evidence has accumulated recently pointing to a role in spatial memory for each of the two posterior parahippocampal subdivisions. For example, lesions in rats of the postrhinal cortex, considered to be the rodent equivalent of the monkey's parahippocampal cortex (Burwell and Amaral, 1998), were found to impair place-specific fear conditioning (Bucci et al., 2000; Burwell et al., 2002). Also, compared with a familiar spatial arrangement of a set of objects, novel rearrangements of the same set produced greater c-fos activation of postrhinal cortex in rats (Wan et al., 1999), and, after lesions of parahippocampal cortex in monkeys, failed to elicit the normal increase in viewing time, implying impaired spatial recognition (Nemanic and Bachevalier, 2002). Similarly, although the parasubiculum/presubiculum represents only $\sim 20 \%$ of the posterior parahippocampal region (Table 1 ), it is likely to make an important contribution to spatial memory given the finding in both rats and monkeys that this tissue contains head-direction cells (Taube, 1995; Taube et al., 1996; Robertson et al., 1999). Indeed, reports indicate that lesions of this tissue in rats impair both working and long-term memory for spatial locations (Kesner and Giles, 1998; Liu et al., 2001).

\section{Memory for places versus object-place associations}

As noted earlier, the evidence obtained by Angeli et al. (1993) suggested that the impairment produced by hippocampectomy in remembering two different object-place pairings on each trial was a secondary consequence of a more fundamental impairment in remembering two different places. One of the possibilities examined in the present study is that this relationship between the two deficits reflects the normal operation of a functional anatomical hierarchy (Mishkin et al., 1997). Specifically, the notion was that the hippocampus, in receipt of inputs from both the anterior and posterior parahippocampal regions, was responsible for combining object recognition mediated by the anterior region with place recognition mediated by the posterior region, thereby enabling the recognition of object-place associations. According to that notion, a posterior parahippocampal lesion would lead to memory deficits both for place and object-place association, just as was found. However, the latter deficit should have been the indirect result of depriving the hippocampus of spatial information, because the process of associating an object and a place was posited to be directly dependent on the hippocampus, and this was not confirmed. Apparently, both place memory and, derivatively, object-place memory, at least as tested here (see below), depend instead on the posterior parahippocampal region and its extrahippocampal projections.

\section{Relationship to recent findings in humans}

Although spatial memory in humans, like that in animals, was long considered to depend mainly on the hippocampus, new evidence implicates the posterior parahippocampal region in hu- 
man ability as well. Thus, functional neuroimaging studies have shown that this region is activated during object-location memory (Owen et al., 1996; Johnsrude et al., 1999) and during encoding and retrieval of topographical information present in visuospatial scenes (Aguirre et al., 1996, 1998; Maguire, 1997; Epstein and Kanwisher, 1998; Maguire et al., 1998; Epstein et al., 1999; Burgess et al., 2001; Rombouts et al., 2001). Even more directly, spatial memory deficits have been reported in patients with medial temporal lobe damage that appears to have affected mainly the posterior parahippocampal region (Landis et al., 1986; Habib and Sirigu, 1987; Maguire et al., 1996; Bohbot et al., 1998; Barrash et al., 2000; Luzzi et al., 2000; Ploner et al., 2000).

Despite these potential parallels between the findings in humans and animals, the present results also pose a cross-species puzzle. An impairment in patients with selective hippocampal damage, i.e., damage that seems to spare the subhippocampal cortices (Schoppik et al., 2001), was obtained on a test of objectplace memory similar in many respects to the one used here (Vargha-Khadem et al., 1997; Adlam et al., 2002; Holdstock et al., 2002). There were also differences between the tasks given to the patients and monkeys, however, perhaps the major one being that the memory demands were far greater for the patients, who were required to remember a list of 20 object-place associations rather than just 2. Whether placing greater demands on objectplace memory by increasing list lengths and delays would uncover a deficit in monkeys with selective hippocampal damage remains to be determined.

\section{References}

Adlam A, Incisa della Rocchetta A, Gadian D, Mishkin M, Vargha-Khadem F (2002) Recognition memory in patients with developmental amnesia. Soc Neurosci Abstr 28:582.10.

Aguirre GK, Detre JA, Aslop DC, D'Esposito M (1996) The parahippocampus subserves topographical learning in man. Cereb Cortex 6:823-829.

Aguirre GK, Zarahn E, D’Esposito M (1998) Neural components of topographical representation. Proc Natl Acad Sci USA 95:839-846.

Alvarado MC, Wright AA, Bachevalier J (2002) Object and spatial relational memory in adult rhesus monkeys is impaired by neonatal lesions of the hippocampal formation but not the amygdaloid complex. Hippocampus 12:421-433.

Andersen RA, Asanuma C, Essick G, Siegel RM (1990) Corticocortical connections of anatomically and physiologically defined subdivisions within the inferior parietal lobule. J Comp Neurol 296:65-113.

Angeli SJ, Murray EA, Mishkin M (1993) Hippocampectomized monkeys can remember one place but not two. Neuropsychologia 31:1021-1030.

Barrash J, Damasio H, Adolphs R, Tranel D (2000) The neuroanatomical correlates of route learning impairment. Neuropsychologia 38:380-936.

Bohbot VD, Kalina M, Stepankova K, Spackova N, Petrides M, Nadel L (1998) Spatial memory deficits in patients with lesions to the right hippocampus and to the right parahippocampal cortex. Neuropsychologia 36:1217-1238.

Bucci DJ, Phillips RG, Burwell RD (2000) Contributions of postrhinal and perirhinal cortex to contextual information processing. Behav Neurosci 114:882-894.

Burgess N, Maguire EA, Spiers HJ, O’Keefe J (2001) A temporoparietal and prefrontal network for retrieving the spatial context of lifelike events. NeuroImage 14:439-453.

Burwell RD, Amaral DG (1998) Cortical afferents of the perirhinal, postrhinal, and entorhinal cortices of the rat. J Comp Neurol 398:1-27.

Burwell RD, Bucci DJ, Wiig KA, Saddoris MP, Sanborn MR (2002) Experimental lesions of the parahippocampal region in rats. In: The parahippocampal region: organization and role in cognitive functions (Witter MP, Wouterlood FG, eds), pp 217-238. New York: Oxford UP.

Cavada C, Goldman-Rakic PS (1989) Posterior parietal cortex in rhesus monkey: I. Parcellations of areas based on distinctive limbic and sensory corticocortical connections. J Comp Neurol 287:393-421.

Ding SL, Van Hoesen G, Rockland KS (2000) Inferior parietal lobule pro- jections to the presubiculum and neighboring ventromedial temporal cortical areas. J Comp Neurol 425:510-530.

Epstein R, Kanwisher N (1998) A cortical representation of the local visual environment. Nature 392:598-601.

Epstein R, Harris A, Stanley D, Kanwisher N (1999) The parahippocampal place area: recognition, navigation, or encoding? Neuron 23:115-125.

Gaffan D (1994) Scene-specific memory for objects: a model of episodic memory impairment in monkeys with fornix transection. J Cognit Neurosci 6:305-320.

Goldman-Rakic PS, Selemon LD, Schwartz ML (1984) Dual pathways connecting the dorsolateral prefrontal cortex with the hippocampal formation and parahippocampal cortex in the rhesus monkey. Neuroscience 12:719-743.

Habib M, Sirigu A (1987) Pure topographical disorientation: a definition and an anatomical basis. Cortex 16:525-542.

Hampstead BM, Hampton RR, Murray EA (2001) Selective hippocampal damage impairs spatial memory in an open-field test in rhesus monkeys. Soc Neurosci Abstr 27:314.4.

Holdstock JS, Mayes AR, Roberts N, Cezayirli E, Isaac CL, O'Reilly RC, Norman KA (2002) Under what conditions is recognition spared relative to recall after selective hippocampal damage in humans? Hippocampus 12:341-351.

Johnsrude IS, Owen AM, Crane J, Milner B, Evans AC (1999) A cognitive activation study of memory for spatial relationships. Neuropsychologia 37:829-841.

Kesner RP, Giles R (1998) Neural circuit analysis of spatial working memory: role of pre- and parasubiculum, medial and lateral entorhinal cortex. Hippocampus 8:416-423.

Landis T, Cummings JL, Benson DF, Palmer EP (1986) Loss of topographic familiarity: an environmental agnosia. Arch Neurol 43:132-136.

Liu P, Jarrard LE, Bilkey DK (2001) Excitotoxic lesions of the pre- and parasubiculum disrupt object recognition and spatial memory processes. Behav Neurosci 115:112-124.

Luzzi S, Pucci E, Di Bella P, Piccirilli M (2000) Topographical disorientation consequent to amnesia of spatial location in a patient with right parahippocampal damage. Cortex 36:427-434.

Maguire EA (1997) Hippocampal involvement in human topographical memory: evidence from functional imaging. Philos Trans R Soc Lond B Biol Sci 352:1475-1480.

Maguire EA, Burke T, Phillips J, Staunton H (1996) Topographical disorientation following unilateral temporal lobe lesions in humans. Neuropsychologia 34:993-1001.

Maguire EA, Burgess N, Donnett JG, O’Keefe J, Frith CD (1998) Knowing where things are: parahippocampal involvement in encoding objects locations in virtual large-scale space. J Cogit Neurosci 10:61-76.

Malkova L, Mishkin M (1997) Memory for the location of objects after separate lesions of the hippocampus and parahippocampal cortex in rhesus monkeys. Soc Neurosci Abstr 23:12.

Malkova L, Mishkin M, Bachevalier J (1995) Long-term effects of selective neonatal temporal lobe lesions on learning and memory in monkeys. Behav Neurosci 109:212-226.

Malkova L, Lex CK, Mishkin M, Saunders RC (2001) MRI-based evaluation of locus and extent of neurotoxic lesions in monkeys. Hippocampus 11:361-370.

Mishkin M, Suzuki WA, Gadian DG, Vargha-Khadem F (1997) Hierarchical organization of cognitive memory. Philos Trans R Soc Lond B Biol Sci 352:1461-1467.

Murray EA, Mishkin M (1998) Object recognition and location memory in monkeys with excitotoxic lesions of the amygdala and hippocampus. J Neurosci 18:6568-6582.

Murray EA, Baxter MG, Gaffan D (1998) Monkeys with rhinal cortex damage or neurotoxic hippocampal lesions are impaired on spatial scene learning and object reversals. Behav Neurosci 112:1291-1303.

Morris R, Petrides M, Pandya DN (1999a) Architecture and connections of retrosplenial area 30 in the rhesus monkey (Macaca mulatta). Eur J Neurosci 9:662-675.

Morris R, Pandya DN, Petrides M (1999b) Fiber system linking the middorsolateral frontal cortex with the retrosplenial/presubicular region in the rhesus monkey. J Comp Neurol 407:183-192.

Nemanic S, Bachevalier J (2002) Roles of the hippocampal formation, perirhinal cortex and areas TH/TF in spatial recognition in monkeys. Soc Neurosci Abstr 28:585.1. 
O'Keefe J, Nadel L (1978) The hippocampus as a cognitive map. Oxford, UK: Clarendon.

Owen AM, Milner B, Petrides M, Evans AC (1996) A specific role for the right parahippocampal gyrus in the retrieval of object-location: a positron emission tomography study. J Cognit Neurosci 8:588-602.

Pandya DN, Van Hoesen GW, Mesulam MM (1981) Efferent connections of the cingulate gyrus in the rhesus monkey. Exp Brain Res 42:319-330.

Parkinson JK, Murray EA, Mishkin M (1988) A selective mnemonic role for the hippocampus in monkeys: memory for the location of objects. J Neurosci 8:4159-4167.

Ploner CJ, Gaymard BM, Rivaud-Pechoux S, Baulac M, Clemenceau S, Samson S, Pierrot-Deseilligny C (2000) Lesions affecting the parahippocampal cortex yield spatial memory deficits in humans. Cereb Cortex 10:1211-1216.

Robertson RG, Rolls ET, Georges-Francois P, Panzeri S (1999) Head direction cells in the primate presubiculum. Hippocampus 9:206-219.

Rombouts SA, Barkhof F, Witter MP, Machielson WC, Scheltens P (2001) Anterior medial temporal lobe activation during attempted retrieval of encoded visuospatial scenes: an event-related fMRI study. NeuroImage 14:67-76.

Rosene DL, van Hoesen GW (1987) The hippocampal formation of the primate brain. A review of some comparative aspects of cytoarchitecture and connections. In: Cerebral cortex, Vol 6 (Jones EG, Peters A, eds), pp 345-456. New York: Plenum.

Saunders RC, O’Boyle Jr VJ (1993) Repair of cranial defects with Teflon: a method of cranioplasty in monkeys. J Neurosci Methods 47:163-167.

Saunders RC, Aigner TG, Frank JA (1990) Magnetic resonance imaging of the rhesus monkey brain: use for stereotactic neurosurgery. Exp Brain Res 81:443-446.

Scharfman HE, Witter MP, Schwarcz R (2000) Preface. In: The parahippocampal region. Implications for neurological and psychiatric diseases,
Vol 911(Scharfman HE, Witter MP, Schwarcz R, eds), pp ix-xiii. New York: New York Academy of Sciences.

Schoppik D, Gadian DG, Connelly A, Mishkin M, Vargha-Khadem F, Saunders RC (2001) Volumetric measurement of the subhippocampal cortices in patients with developmental amnesia. Soc Neurosci Abstr 27:1400.

Selemon LS, Goldman-Rakic PS (1988) Common cortical and subcortical targets of the dorsolateral prefrontal and posterior parietal cortices in the rhesus monkey: evidence for a distributed neural network subserving spatially guided behavior. J Neurosci 8:4049-4068.

Seltzer B, Pandya DN (1976) Some cortical projections to the parahippocampal area in the rhesus monkey. Exp Neurol 50:146-160.

Seltzer B, Pandya DN (1984) Further observations on parieto-temporal connections in the rhesus monkey. Exp Brain Res 55:301-312.

Seltzer B, van Hoesen GW (1979) A direct inferior parietal lobule projection to the presubiculum in the rhesus monkey. Brain Res 179:157-161.

Suzuki WA, Amaral DG (1994) Perirhinal and parahippocampal cortices of the macaque monkey: cortical afferents. J Comp Neurol 350:497-533.

Taube JS (1995) Place cells recorded in the parasubiculum of freely moving rats. Hippocampus 5:569-583.

Taube JS, Goodridge JP, Golob EJ, Dudchenko PA, Stackman RW (1996) Processing the head direction cell signal: a review and commentary. Brain Res Bull 40:477-486.

Vargha-Khadem F, Gadian DG, Watkins KE, Connelly A, Van Paesschen W, Mishkin M (1997) Differential effects of early hippocampal pathology on episodic and semantic memory. Science 277:376-380.

von Bonin G, Bailey P (1947) The neocortex of Macaca mulatta. Urbana, IL: University of Illinois.

Wan H, Aggleton JP, Brown MW (1999) Different contributions of the hippocampus and perirhinal cortex to recognition memory. J Neurosci 19: $1142-1148$. 